\title{
Intelligent Data Mining Algorithm Application in Enterprise Financial Management Strategy Optimization: A E-commerce Perspective
}

\author{
Lili Jia \\ Taishan University, Taian 271021, Shandong, China \\ jialli@126.com
}

\begin{abstract}
With the development of electronic commerce, the management mode of enterprises has been changed, E-business enterprises will also create new financial model, suitable for electronic commerce situation. In this paper, the author first put forward the data mining method based on SVM algorithm. Based on the empirical analysis, author research on the influence factors of e-commerce enterprise financial management mode, and makes a detailed analysis of the relationship between the environment, the network and the performance. For the electronic business enterprise, the solvency, development potential, innovation ability and adapt to the environment of the organization flexibility is the important index of E-enterprise performance evaluation index system.
\end{abstract}

Keywords: Data mining, E-commerce perspective, financial management, budget accuracy

\section{Introduction}

Since the Internet has changed from Web1.0 to Web2.0, the function system and interactive design of the network community have become diversified and systematic, and the interface and module of the users have become more and more life. In order to adapt to the new environment and new needs, the concept of "network finance" arises at the historic moment[1]. The concept of network finance and the implementation of the corresponding strategy is a major innovation of enterprise financial management theory. Electronic commerce is around the world in a wide range of commercial and trading activities[2]. According to the Internet, open network environment as the basis, based on the browser/server mode, online shopping, merchant's consumers between online transactions and online electronic payment and a variety of business activities, trading activities, financial activities and related comprehensive service activities of a new business model. Role of e-commerce enterprises in economic development has been widely recognized, e-commerce enterprises on Cultivation of innovation ability, enhance corporate performance, transformation of industrial structure, promoting employment, raising per capita income level and the growth of the regional economy is extremely important[3-4]. Since the advent of electronic commerce, its impact on human activities has penetrated into all aspects, and will become a necessity in the foreseeable future. Ecommerce as the situation of enterprise business activities will have an important impact on enterprise financial management from theory to practice[5]. Enterprise financial management mode is present in the overall management of the enterprise within the framework, designed to realize the goal of enterprise's overall strategy, the overall goal of financial management system, management, personnel management, project division elements of the organic combination. Therefore, the enterprise financial management model must be fit for the environment, modular, can be updated by the strategic objectives of the enterprise, and the reverse effect on the strategic objectives of the enterprise. In the context of electronic commerce, the traditional financial management 
theories of the enterprises need to be updated, the traditional pattern of enterprise financial management has been difficult to adapt to the requirements of the times and therefore to explore the situation of electronic commerce under suitable for enterprise management, the survival and development, especially for electronic commerce enterprise financial management mode.

In the era of electronic commerce, the management mode of enterprises will be changed, and the accounting theory and accounting practice will also be adjusted accordingly, and will also give birth to new financial model suitable for the situation of electronic business[6]. Electronic commerce is refers to the business activities in the Internet, intranet and value-added network use of microcomputer technology and network communication technology of transactions electronically for trading activities and related service activities, is a traditional business activities of each link of the electronic networking[7-8]. Main business using the Internet as the representative of the information transmission tool, between the internal, superior supplier, lower level dealers, customers and benefits related, through the electronic tool sharing information and complete the electronic business process reengineering, improve the efficiency of all the activities of enterprises in the production and sales, bank deposit flow, cash flow and the strategic decision.

In this paper, we studied the data mining algorithm based on SVM, and analyze the electronic commerce situation, enterprise financial model and enterprise performance and other elements into the same overall framework. Then make a detailed analysis of the internal relations between the elements, and further improve the relevant enterprise financial management theory. Draw lessons from domestic and international relevant research results, in-depth study of e-commerce business process, and the influence factors of electronic business enterprise financial management mode. And build a suitable ecommerce business, in accordance with the characteristics of e-commerce business model of financial management. To form a large e - commerce enterprises as the research object, starting from the influencing factors, in-depth study of the qualitative and quantitative relationship between several factors of the research process. Therefore, this paper not only theoretically fill the situation about electronic business financial management mode and the electronic commerce enterprise financial management mode of blank, more relations environment, network, performance of detailed analysis, to further improve the enterprise financial management theory.

\section{Data Mining based on SVM Algorithm}

\subsection{Structural Risk Minimization}

Since 1990s, the neural network algorithm has gradually developed into one of the increasingly sophisticated intelligent methods. Neural network is a complex network system which is formed by the connection of a large number of single neurons. Neural network system has a certain adaptability and nonlinear mapping ability. Vector Machine Support (SVM) method is proposed as the problem of the neural network method becomes more and more prominent. Support vector machine is developed on the basis of the small sample statistical theory. SVM is different from the neural network approach based on empirical risk minimization, which is based on the principle of structural risk minimization. It has strong generalization ability, and can effectively solve the problem of small sample size. Because of the existence of these advantages, SVM algorithm is widely used in the field of data mining, but also by the scholars more and more attention. Support vector machine is a new machine learning method based on statistical learning theory, in order to find an optimal function $f\left(\mathrm{x}, \pi_{0}\right)$ to approximate the links between the input $\mathrm{x}$ and the output $\mathrm{y}$ and theory requirements follows the minimization of the expected risk: 
$R(\pi)=\int L(y, f(x, \pi)) d F(x, y)$

In formula (1), the probability density function is unknown, so the above expectation risk can not be directly calculated. Therefore, the expected risk of $\mathrm{R}(\pi)$ to replace the experience of risk:

$R_{\text {emp }}(\pi)=\frac{1}{l} \sum_{i=1}^{l} L\left(y_{i}, f\left(x_{i}, \pi\right)\right)$

If the expectations of the risk $\mathrm{R}(\pi)$ and empirical risk $\mathrm{R}_{\mathrm{emp}}(\pi)$ according to the convergence of probability $\mathrm{p}$ to the same limit inf $\mathrm{R}(\pi)$ is called empirical risk minimization principle is consistent.

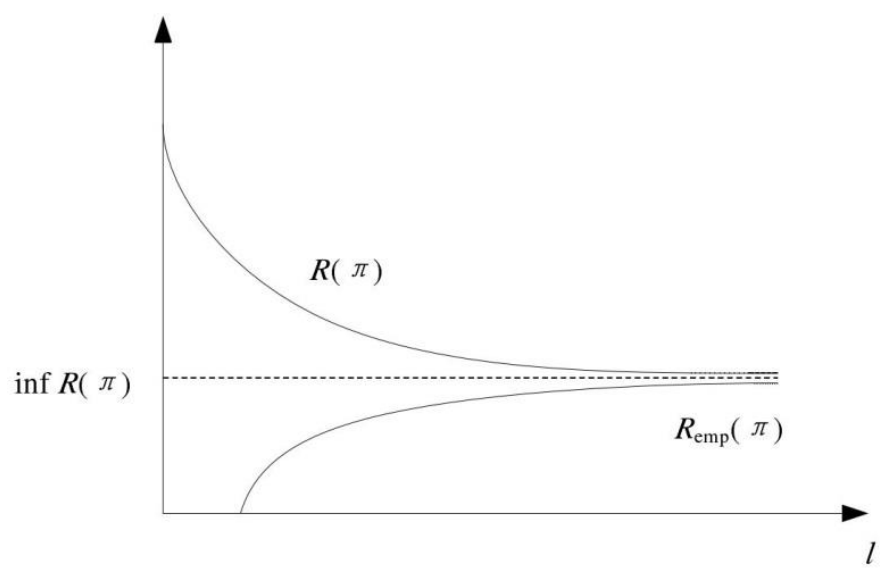

Figure 1. Consistency of Learning Process

Vapnik after in-depth study put forward the principle of structural risk minimization (SRM), that is:

$R(\pi) \leq R_{\text {emp }}(\pi)+\sqrt{\frac{h \ln \left(\frac{2 l}{h}\right)-\ln \left(\frac{\eta}{4}\right)}{l}}$

Among them, 1 is the number of sample points, $\eta$ parameters $(0 \leq \eta \leq 1)$, $h$ is a function of the dimension of $\mathrm{f}$, referred to as $\mathrm{VC}$ dimension.

\subsection{Support Vector Machine}

Compared with the previous theory, the SVM theory is widely used in many fields, such as electric power, economy and medicine, with the advantages of small training samples, strong generalization ability and easy to get the global optimal solution. Support vector machine has 3 basic functions: pattern recognition, regression prediction, probability density estimation.

First, the linear separable problem is analyzed. For linearly separable training sets:

$T=\left\{\left(x_{1}, y_{1}\right),\left(x_{2}, y_{2}\right), K,\left(x_{n}, y_{n}\right)\right\}$

Hypothesis existence discriminant function:

$f(x)=\operatorname{sgn}((\omega \cdot x)+b)$ 
Linear case, the optimal classification of the idea of the super plane can be described in Figure 2. $\mathrm{H}$ is a solid line classification; solid point and hollow point obliquely upward downward respectively represent two types of samples. $\mathrm{Hl}$ and $\mathrm{H} 2$ is parallel to the plane of the classification plane, which is determined by the nearest sample of all kinds of middle and out of line, and the distance between them is defined as the classification interval (margin). The plane of the two classes of correctly separated is called the optimal classification face, the training error rate is 0 , the maximum classification interval is called the best classification hyper plane. Support vector refers to the H1, H2 corresponding to the training sample points.

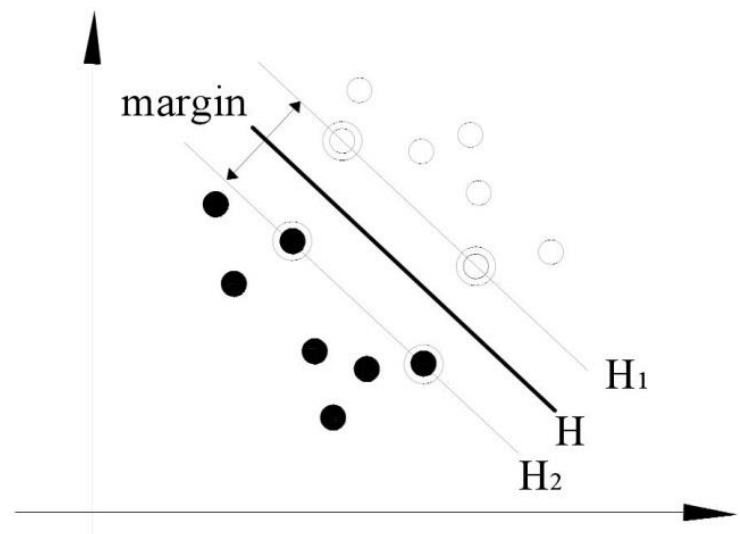

Figure 2. The Optimal Separating Hyperplane

In order to maximize the classification of the two types of samples, it is needed to maximize the distance, that is, structural optimization problem:

$\min \frac{1}{2}\|\omega\|^{2}$

s.t. $\quad y_{i}(\omega \cdot x+b)-1 \geq 0$

When the linearity is not available, there are some sample points which are not satisfied, then the formula is introduced into the:

$\min \frac{1}{2}\|\omega\|^{2}+c \sum_{i=1}^{n} \xi_{i}$

s.t. $\quad y_{i}(\omega \cdot x+b) \geq 1-\xi_{i}$

By introducing Lagrange multipliers, the original constrained optimization problem is transformed into a dual problem:

$\min \frac{1}{2} \sum_{i=1}^{n} \sum_{j=1}^{n} y_{i} y_{j} \alpha_{i} \alpha_{j}\left(x_{i} \cdot x_{j}\right)+\sum_{i=1}^{n} \alpha_{i}$

s.t. $\quad \sum_{i=1}^{n} y_{i} \alpha_{i}=0$

The solution can be obtained by solving the equation:

$\omega=\sum_{i=1}^{n} \alpha_{i} y_{i} x_{i}$ 
$b=y_{i}-\sum_{i=1}^{n} y_{i} \alpha_{i}\left(x_{i} \cdot x_{j}\right)$

Then we get the linear discriminant function:

$f(x)=\operatorname{sgn}\left(\sum_{i=1}^{n} \alpha_{i} y_{i}\left(x_{i} \cdot x_{j}\right)+b\right)$

In reality, there are more and more nonlinear cases, which must be extended to the linear case. The training sample characteristics by mapping function $\varnothing(\mathrm{x})$ mapped to high dimension linear space and put the $\varnothing(\mathrm{x})$ into the optimization problem:

$\min \frac{1}{2} \sum_{i=1}^{n} \sum_{j=1}^{n} y_{i} y_{j} \alpha_{i} \alpha_{j}\left(\phi\left(x_{i}\right) \cdot \phi\left(x_{j}\right)\right)+\sum_{i=1}^{n} \alpha_{i}$

\section{Model and Hypothesis}

\subsection{E-business Enterprise Financial Management Mode}

As mentioned earlier, compared to e-commerce enterprises and traditional enterprises, particularly emphasized behavioral accounting information, and big data, "cloud" financial, financial information of the enterprise management and higher. Therefore, it is necessary to independent of the management pattern of financial information, as belonging to the fifth mode of e-commerce enterprise financial management mode. Need to pay attention to is that accounting information disclosure mode and financial information management mode for the operation of the "information", but cannot be confused, accounting information disclosure mode is mainly responsible for external information disclosure, more inclined to information products provide, and financial information management mode is mainly responsible for internal information processing, more inclined to internal information processing, is two categories, two kinds of the meaning of "information", the former is more similar to the message and symbols, the latter is more similar to the data and records.

In addition, compared to e-commerce enterprises and traditional enterprises, capital intensive, application and operation of a large number of capital, and through the financing of capital allocation, enhance the efficiency of using capital; while access to the new point of growth through investment, obtain higher investment income. The efficiency of capital management directly determines whether the financial management of ecommerce enterprises is effective or not, and to a large extent affect the success or failure of e-commerce business. E-commerce enterprise performance evaluation model of operating performance based on the methodology of the economics, management, financial analysis technology, through the construction of specific performance evaluation system and the corresponding evaluation criteria, evaluation procedure, comprehensive financial indicators and non-financial indicators, to the electronic commerce enterprise specific business during the period of quantitative and qualitative evaluation, provide the basis for the evaluation of enterprise development and for the formulation of business strategy to provide reference of financial management mode.

\subsection{Hypothesis Proposed}

For e-commerce enterprises, as a result of a higher degree of decentralization, the specific implementation (such as project group, division, division/subsidiary) higher decision-making participation degree and strong property rights, the in budget execution plan tend to consider the short-term performance of region responsible for their own individual interests or the regional business, and top management interest exists not fully 
fit. If budget larger binding, discipline and strong, performance appraisal and the reward is low, the implementation of the layer in strict compliance with budget plan strong motivation; if the budget adjustment procedure is not flexible enough, management flexibility is bigger, a high performance after a higher reward, the execution layer will do not comply with the budget and seek greater interests motivation. Therefore, between the management and the executive layer, the basic budget game structure is formed. Based on the above analysis, this paper puts forward the following assumptions:

Hypothesis 1A: the degree of decentralization of financial organization has a significant positive impact on budget accuracy.

Hypothesis 1b: financial organizational learning capability has a significant positive impact on budget accuracy.

Corporate budgeting more accurate, at the end of the year of assessment and performance, the more you can according to the implementation of the budget, direct and effective reaction corporate performance, and corporate budgeting if many errors and flaws is very large, it will cause some problems to the enterprise performance evaluation, thereby affecting the accuracy of enterprise performance evaluation. Therefore, this paper puts forward the hypothesis

Hypothesis 2: Budget accuracy has a significant positive impact on the accuracy of enterprise performance evaluation.

Enterprise performance evaluation of the accuracy of accounting information disclosure of the extent of voluntary influence, the enterprise can accurately evaluate enterprise performance; more on their actual business situation has a accurate understanding and reporting accounting information motivation is smaller. Therefore, this paper puts forward the following assumptions:

Hypothesis 3: the accuracy of enterprise performance evaluation has a significant positive impact on the degree of voluntary accounting information disclosure.

\section{Empirical Research}

\subsection{Scale Design}

According to the existing academic research achievements, this paper the metrics, gives out the related financial organizational decentralization three items: the electronic commerce enterprise in decision making, appropriate delegation of decision-making authority, and can let employees to participate in a wide range of decision process FQ1; subsidiary of the electronic commerce enterprise, company, Department has a larger financial decision-making right (fq2); the electronic commerce enterprise financial department daily work can not subject to management and other departments interference independently (fq3). Measure the organizational learning ability of the enterprise mainly includes the ability to adapt to the environment, the ability of the enterprise to develop the new technology and the innovation ability of the enterprise's business model. Based on the above point of view, the above index is given for relevant financial and organizational learning capability of three items: the electronic commerce enterprise to the outside environment adaptation ability (xx1); the e-commerce enterprises to apply new technologies, development new products, explore new business model (XX2); the electronic commerce enterprise has a good learning atmosphere (XX3). As shown in the following table: 
Table 1. Decentralization of Financial Organization

\begin{tabular}{|c|c|}
\hline $\begin{array}{c}\text { Measurement } \\
\text { dimension }\end{array}$ & Item \\
\hline \multirow{2}{*}{$\begin{array}{c}\text { Degree of } \\
\text { decentralization } \\
\text { of financial } \\
\text { organization }\end{array}$} & $\begin{array}{c}\text { When making decisions, the E-commerce enterprise can appropriately } \\
\text { lower the decision-making power and make the employees participate } \\
\text { in the decision-making process. }\end{array}$ \\
\cline { 2 - 2 } & $\begin{array}{c}\text { The E- commerce enterprise's subsidiary company, the branch, the } \\
\text { business unit has the bigger financial decision-making power }\end{array}$ \\
\cline { 2 - 2 } & $\begin{array}{c}\text { The daily work of the Finance Department of the E-commerce } \\
\text { enterprise can not be done by the management and other departments. }\end{array}$ \\
\hline
\end{tabular}

Table 2. Financial Organization Learning Ability

\begin{tabular}{|c|c|}
\hline $\begin{array}{l}\text { Measurement } \\
\text { dimension }\end{array}$ & Item \\
\hline \multirow{3}{*}{$\begin{array}{l}\text { Financial } \\
\text { organization } \\
\text { learning } \\
\text { ability }\end{array}$} & The adaptability of the E-business enterprise to the external environment \\
\hline & $\begin{array}{l}\text { The ability to apply new technologies, develops new products, and } \\
\text { explores new business models. }\end{array}$ \\
\hline & e E- commerce enterprise has better learning organization atmosphere \\
\hline
\end{tabular}

Susso (2009) will be financial information for the classification and points for decision of information and evaluation information and decision-making information is refers to the enterprise financial decision information and enterprise financial policy risk preference, and evaluation of information including financial statements and audit reports. In this paper, based on the accounting information voluntary disclosure setting the three items: the e-commerce enterprises willing to disclose to the public the financial policies of risk preference (zy1); the e-commerce enterprises voluntarily to the public disclosure of the financial statements and audit reports $\mathrm{ZY} 2$; the electronic commerce enterprise is willing to to the public about their financial situation (zy3). As shown in the following table:

Table 3. Voluntary Accounting Information Disclosure

\begin{tabular}{|c|c|}
\hline $\begin{array}{c}\text { Measurement } \\
\text { dimension }\end{array}$ & Item \\
\hline \multirow{3}{*}{$\begin{array}{l}\text { Voluntary } \\
\text { accounting } \\
\text { information } \\
\text { disclosure }\end{array}$} & $\begin{array}{l}\text { E-commerce companies are willing to disclose to the public the risk } \\
\text { appetite of their financial policies }\end{array}$ \\
\hline & $\begin{array}{l}\text { E-commerce enterprise voluntarily disclose its financial statements and } \\
\text { audit reports to the public }\end{array}$ \\
\hline & $\begin{array}{l}\text { E-commerce companies are willing to talk to the public and their } \\
\text { financial situation }\end{array}$ \\
\hline
\end{tabular}

To evaluate the effectiveness of enterprise budget management, it is necessary to investigate the incentive mechanism, which is the ability to adjust the budget in order to make it fit the actual operating conditions. The three items of budget accuracy measure: the electronic commerce enterprise's actual operating status and budget deviation degree (ys1); the e-commerce enterprises according to the actual situation, adjust the budget (YS2); the electronic commerce enterprise in budget preparation, budget for the period of major events to a certain degree of forward-looking and set aside the space budget (ys3). As shown in the following table: 


\section{Table 4. Budget Accuracy Measure}

\begin{tabular}{|c|c|}
\hline $\begin{array}{c}\text { Measurement } \\
\text { dimension }\end{array}$ & Item \\
\hline \multirow{3}{*}{$\begin{array}{c}\text { Budget } \\
\text { accuracy }\end{array}$} & $\begin{array}{c}\text { The degree of deviation of the actual operating conditions and budget of } \\
\text { the E-commerce enterprise }\end{array}$ \\
\cline { 2 - 2 } & $\begin{array}{c}\text { E-business enterprise according to the actual situation of the ability to } \\
\text { adjust the budget }\end{array}$ \\
\cline { 2 - 2 } & $\begin{array}{c}\text { E- business enterprise in the preparation of the budget, the budget period } \\
\text { of major events to a certain extent, and set aside budget space }\end{array}$ \\
\hline
\end{tabular}

\subsection{Factor Analysis}

Component analysis is a commonly used method for factor analysis in the extraction of shared factors, and the emphasis is also on the variance of the data, which is different from the correlation between the key explanatory variables of the factor analysis. In this paper, the principal component analysis is used to carry out factor analysis, and the reliability and validity are tested to ensure that the scale is reliable. Reliability analysis is using the coefficient Cronbach's $\alpha$ analysis method, the $\alpha$ coefficient of the scale and the removal of each subtopic of the alpha coefficient test.

Table 5. Factor Analysis

\begin{tabular}{|c|c|c|c|c|c|c|}
\hline \multicolumn{7}{|c|}{ Explained the total variance } \\
\hline Ingredients & \multicolumn{5}{|c|}{ Initial eigenvalue } & \multicolumn{3}{|c|}{ Extraction square and loading } \\
\hline Factor & total & $\begin{array}{c}\text { Variance } \\
\%\end{array}$ & $\begin{array}{c}\text { Cumulative } \\
\%\end{array}$ & total & $\begin{array}{c}\text { Variance } \\
\%\end{array}$ & $\begin{array}{c}\text { Cumulative } \\
\%\end{array}$ \\
\hline FQ1 & 2.351 & 78.367 & 78.367 & 2.351 & 78.367 & 78.367 \\
\hline FQ2 & .378 & 12.600 & 90.967 & & & \\
\hline FQ3 & .271 & 9.033 & 100.000 & & & \\
\hline XX1 & 2.177 & 72.567 & 72.567 & 2.177 & 72.567 & 72.567 \\
\hline XX2 & .452 & 15.067 & 87.634 & & & \\
\hline XX3 & .371 & 12.366 & 100.000 & & & \\
\hline ZY1 & 2.095 & 69.833 & 69.833 & 2.095 & 69.833 & 69.833 \\
\hline ZY2 & .508 & 16.933 & 86.766 & & & \\
\hline ZY3 & .371 & 13.234 & 100.000 & & & \\
\hline YS1 & 2.155 & 71.833 & 71.833 & 2.155 & 71.833 & 71.833 \\
\hline YS2 & .484 & 16.133 & 87.967 & & & \\
\hline YS3 & .361 & 12.033 & 100.000 & & & \\
\hline
\end{tabular}

From the table we can see that financial organizational decentralization, financial organization learning ability, accounting information disclosure voluntary degree and budget accuracy of three items through principal component analysis, and the characteristic values corresponding to the principal components could explain the $78.367 \%, 72.567 \%, 69.833 \%, 71.833 \%$ variance, illustrate the scale through the principal component analysis. At the same time, we analyze the reliability and validity of the data, and the results are shown in Table 6, Table 7.

The Cronbach's coefficient $>0.7$ and the removal any alpha coefficients were not significantly increased, so the table by means of reliability test. As shown above, the scale $>0.7 \mathrm{KMO}$, each factor load are $>0.5$, and through the significant test, the data is valid. 
Table 6. The Reliability Analysis

\begin{tabular}{|c|c|c|}
\hline Facor & Cronbach $\alpha$ coefficient & $\begin{array}{c}\text { Cronbach } \alpha \text { coefficient } \\
\text { after removal of the item }\end{array}$ \\
\hline $\begin{array}{c}\text { Financial decentralization } \\
\text { degree }\end{array}$ & $\mathbf{0 . 8 7 4}$ & \\
\hline FQ1 & & 0.826 \\
\hline FQ2 & 0.859 \\
\hline FQ3 & & 0.793 \\
\hline $\begin{array}{c}\text { Financial organization } \\
\text { learning ability }\end{array}$ & $\mathbb{0 . 7 5 5}$ & \\
\hline XX1 & & 0.743 \\
\hline XX2 & & 0.713 \\
\hline XX3 & & 0.704 \\
\hline $\begin{array}{c}\text { Voluntary accounting } \\
\text { information disclosure }\end{array}$ & $\mathbf{0 . 7 3 4}$ & \\
\hline ZY1 & & 0.712 \\
\hline ZY2 & 0.705 \\
\hline ZY3 & & 0.696 \\
\hline Budget accuracy & $\mathbf{0 . 7 5 7}$ & 0.682 \\
\hline YS1 & & 0.631 \\
\hline YS2 & 0.667 \\
\hline YS3 & & \\
\hline
\end{tabular}

Table 7. Scale Validity Analysis

\begin{tabular}{|c|c|c|c|c|}
\hline Facor & influence factor & Factor load & KMO value & Sig value \\
\hline \multirow{3}{*}{$\begin{array}{c}\text { Financial } \\
\text { decentralization } \\
\text { degree }\end{array}$} & FQ1 & 0.754 & \multirow{3}{*}{0.758} & \multirow{3}{*}{0.000} \\
\hline & FQ2 & 0.686 & & \\
\hline & FQ3 & 0.761 & & \\
\hline \multirow{3}{*}{$\begin{array}{c}\text { Financial } \\
\text { organization } \\
\text { learning ability }\end{array}$} & $\mathrm{XX1}$ & 0.612 & \multirow{3}{*}{0.802} & \multirow{3}{*}{0.000} \\
\hline & XX2 & 0.706 & & \\
\hline & XX3 & 0.577 & & \\
\hline \multirow{3}{*}{$\begin{array}{c}\text { Voluntary } \\
\text { accounting } \\
\text { information } \\
\text { disclosure } \\
\end{array}$} & ZY1 & 0.694 & \multirow{3}{*}{0.722} & \multirow{3}{*}{0.000} \\
\hline & ZY2 & 0.723 & & \\
\hline & ZY3 & 0.561 & & \\
\hline \multirow{3}{*}{ Budget accuracy } & YS1 & 0.775 & \multirow{3}{*}{0.743} & \multirow{3}{*}{0.000} \\
\hline & YS2 & 0.690 & & \\
\hline & YS3 & 0.627 & & \\
\hline
\end{tabular}

\subsection{Structural Equation Test}

Structural equation modeling (SEM) is a very good method in social science research. The method has matured in the eighties of the 20th century, in the field of social science and economics, marketing, management, and other research and sometimes deal with the relationship between multiple causes and multiple results, or will encounter cannot be directly observed variables (i.e., the latent variables), these are the traditional meter method is not a good solution to the problem. The fitting quality of the model needs to be tested by the fit index, as shown in Table 9 . 
Table 8. The Correlation Coefficient

\begin{tabular}{|c|c|c|c|c|c|c|c|c|c|c|c|c|}
\hline factor & FQ1 & FQ2 & FQ3 & XX1 & XX2 & XX3 & ZY1 & ZY2 & ZY3 & YS1 & YS2 & YS3 \\
\hline FQ1 & 1 & & & & & & & & & & & \\
\hline FQ2 & 0.62 & 1 & & & & & & & & & & \\
\hline FQ3 & 0.42 & 0.49 & 1 & & & & & & & & & \\
\hline XX1 & 0.51 & 0.32 & 0.48 & 1 & & & & & & & & \\
\hline XX2 & 0.55 & 0.37 & 0.43 & 0.54 & 1 & & & & & & & \\
\hline XX3 & 0.47 & 0.68 & 0.59 & 0.59 & 0.64 & 1 & & & & & & \\
\hline ZY1 & 0.64 & 0.46 & 0.60 & 0.77 & 0.37 & 0.69 & 1 & & & & & \\
\hline ZY2 & 0.41 & 0.33 & 0.74 & 0.43 & 0.25 & 0.55 & 0.47 & 1 & & & & \\
\hline ZY3 & 0.32 & 0.73 & 0.34 & 0.45 & 0.47 & 0.33 & 0.58 & 0.43 & 1 & & & \\
\hline YS1 & 0.66 & 0.34 & 0.45 & 0.76 & 0.36 & 0.58 & 0.29 & 0.47 & 0.35 & 1 & & \\
\hline YS2 & 0.76 & 0.44 & 0.47 & 0.42 & 0.58 & 0.25 & 0.49 & 0.36 & 0.56 & 0.25 & 1 & \\
\hline YS3 & 0.44 & 0.36 & 0.39 & 0.53 & 0.36 & 0.36 & 0.46 & 0.25 & 0.36 & 0.35 & 0.36 & 1 \\
\hline
\end{tabular}

Table 9. Model Fitting Inspection

\begin{tabular}{|c|c|c|c|}
\hline \multirow{2}{*}{ Evaluation factors } & \multicolumn{3}{|c|}{ Influence degree } \\
\cline { 2 - 4 } & large & commonly & Small \\
\hline theoretical basis & 0.4 & 0.4 & 0.3 \\
\hline practical experience & 0.4 & 0.3 & 0.3 \\
\hline popularity & 0.4 & 0.1 & 0.1 \\
\hline first impression & 0.3 & 0.2 & 0.3 \\
\hline
\end{tabular}

\section{Conclusion}

Role of e-commerce enterprises in economic development has been widely recognized, e-commerce enterprises on Cultivation of innovation ability, enhance corporate performance, transformation of industrial structure, promoting employment, raising per capita income level and the growth of the regional economy is extremely important. With the deepening of the research of electronic commerce, expanding the research angle of ecommerce enterprises, the traditional financial management theories of the enterprises need to be updated, the traditional pattern of enterprise financial management has been difficult to adapt to the needs of the times, therefore explore the E-commerce Context for enterprise management, the survival and development, is especially suitable for the financial management mode of enterprise electronic commerce not only has the theoretical necessity, and the realistic necessity. This paper discusses the part of ecommerce enterprise financial management through the analysis of electronic commerce mode of enterprise's financial management patterns in the measurement of dimensions, was constructed, which can describe the interaction mechanism model. And based on the modes in e-commerce enterprise financial management relationship and the electronic commerce enterprise financial management mode formed mechanism presents a number of hypotheses, through questionnaire survey and statistical analysis of hypothesis verification, and come to the conclusion of empirical research.

Is analyzed in this paper in our country electronic commerce mode of enterprise's financial management problems, and then gives the Countermeasures: decentralization is a major feature of the electronic commerce enterprise, as the premise for the construction of e-commerce enterprise financial organization mode it is necessary to set up Financial Shared Service Center as a financial organization core connection points. Because of the high degree of decentralization, in budgeting, decision layer and execution layer exist certain interests inconsistency is bound to have an around the budget target and whether to amend the budget implementation of the game, in order to reduce the conflicts of 
interests and need to introduce suitable characteristics of incentive mechanism. For ecommerce companies, solvency ability, development potential and produce new products, new services, innovation capacity and adaptation degree of flexibility in the organization's environment is enterprise performance evaluation index system is an important indicator. On the basis of this, the electronic commerce enterprise performance evaluation index system is designed, which is suitable for the e-commerce environment.

\section{References}

[1] V.Bebchuk, "The state of corporate governance research", Review of Financial Studies, vol. 23, (2010), pp. 939-961.

[2] G. Nini and C. Smith, "Creditor control rights,corporate governance, and firm value", Review of Financial Studies, vol. 25, (2012), pp. 1713-1761.

[3] R. Kaplan, "Using the balanced scorecard as a strategic management system. Harvard business review", vol. 74, (1996), pp. 75-85.

[4] A. Shleifer and R.W. Vishny, "A survey of corporate governance", The journal of finance, vol. 52, (1997), pp. 737-783.

[5] R. Aghion, "Incomplete contracts and the theory of the firm: What have we learned over the past 25 years?" The Journal of Economic Perspectives, vol. 25, (2011), pp. 181-197.

[6] V. Acharya, "Corporate governance and value creation: Evidence from private equity", Review of Financial Studies, vol. 26, (2013), pp. 368-402.

[7] T. Jenkinson and C. Mayer, "The assessment: corporate governance and corporate control", Oxford Review of Economic Policy, vol. 8, (2012), pp. 1-10.

[8] A. Edmans, "Governance through trading and intervention: A theory of multiple blockholders", Review of Financial Studies, vol. 7, (2011), pp. 2395-2428.

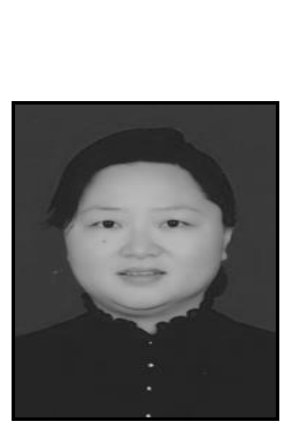

\section{Author}

$<$ Jia Lili $><$ Shandong,China $>$

Current position, grades: the associate professor of financial management, Taishan University, Shandong, China

Scientific interest: Enterprise financial management

Publications: 2 works and more than 20 papers published

Experience: She has teaching experience of 22 years, has completed five scientific research project. 
International Journal of Security and Its Applications

Vol. 10, No. 7 (2016) 